\title{
Coordination of Supply Chain with a Dominant Retailer under Demand Disruptions
}

\author{
Jian Li, ${ }^{1}$ Xiaofang Liu, ${ }^{1}$ Jun ${\mathrm{Wu},{ }^{1} \text { and Fengmei Yang }}^{2}$ \\ ${ }^{1}$ School of Economics and Management, Beijing University of Chemical Technology, Beijing 100029, China \\ ${ }^{2}$ School of Science, Beijing University of Chemical Technology, Beijing 100029, China \\ Correspondence should be addressed to Fengmei Yang; yangfm@mail.buct.edu.cn
}

Received 29 December 2013; Accepted 18 March 2014; Published 23 April 2014

Academic Editor: Chuangxia Huang

Copyright (c) 2014 Jian Li et al. This is an open access article distributed under the Creative Commons Attribution License, which permits unrestricted use, distribution, and reproduction in any medium, provided the original work is properly cited.

\begin{abstract}
We develop a coordination model of a one-manufacturer multi-retailers supply chain with a dominant retailer. We consider the impact of a dominant retailer on the market retail price and his sales promotion opportunity and examine how the manufacturer can coordinate such a supply chain by revenue-sharing contract after demand disruptions. We address the following important research questions in this paper. (i) How do we design an appropriate revenue-sharing contract to coordinate the supply chain with a dominant retailer without demand disruptions? (ii) When demand is disrupted with variations in market scale and price sensitive coefficient, can the original contract still be valid? (iii) How do the demand disruptions affect the coordination mechanism under different disruption scenarios and how should the new contract change? Finally, we generate important insights by both analytical and numerical examples.
\end{abstract}

\section{Introduction}

In the real world, there are some sudden events resulting in the change of demand abruptly, such as exposure of enterprises' own problem, outbreak of infectious diseases, and policy change of the government. Recently, more and more food safety problems are revealed by the media and do harm to the development of relevant industries in China, such as "Sudan red dye" incident and "Melamine" incident. The outbreaks of mad cow disease and swine flu lead to demands for disinfectors and medicines increasing considerably and attack the market of chicken or beef. Besides, government policies and international relationship can also affect market demand and corresponding partners of supply chain. For example, due to strained relationship between China and Japan, sales of Japanese commodities and vehicles slumped in 2012. Therefore, the disruption management and coordination mechanisms of supply chain have become an active research topic in both science and business community. In order to ensure that supply chain is robust enough to handle the demand and supply uncertainties, the researchers have proposed certain coordination models to deal with the disruption risk in supply chain [1-3].
In this paper, we investigate coordination of a onemanufacturer multi-retailers supply chain with one dominant retailer after demand disruptions. As [4] said, in some of today's retailing markets, the dominant retailer is the largest distributor for the manufacture and is the price leader of the market in general. Therefore, we assume that only the dominant retailer can provide the demand-stimulating service to the manufacturer's products. We regard the fringe retailers as a whole, for they are identical. As it is assumed in $[1,5]$, our model is under the assumption of perfect information and all the partners of supply chain are risk-neutral. Moreover, demand disruptions often lead to certain extra deviation costs associated with the total production deviation quantity. In our model, the manufacturer bears these deviation costs totally, which $[6,7]$ supported. Based on these assumptions, we analyze the effect of demand disruptions on supply chain and propose corresponding coordination mechanism by revenue-sharing contracts.

The rest of the paper is organized as follows. The next section reviews related literature. Section 3 outlines our basic model with a dominant retailer and studies how the supply chain is coordinated by revenue-sharing contracts when there are no disruptions. In Section 4, we discuss the response 
strategies that the manufacture and the dominant retailer should do after demand is disrupted. The analytical results are elaborated by numerical examples in Section 5. Finally, Section 6 provides conclusions and points out directions for future research.

\section{Literature Review}

In this paper, the study stems from the intersection of supply chain coordination and disruption management. Recently, large quantities of studies in supply chain management focus on how to design the coordination schemes. Cachon [8] summarized supply chain coordination mechanisms in detail and reviewed the literature excellently. Bernstein and Federgruen [9] designed a nonlinear wholesale contract to coordinate the supply chain with one supplier and competing retailers. Raju and Zhang [4] coordinated the supply chain with a dominant retailer through either quantity discounts or two-part tariffs. Revenue-sharing is a very attractive contract [10], and increasingly manufacturers and retailers are implementing revenue-sharing contracts to coordinate distribution supply chains more effectively [11]. Gerchak and Wang [12] studied wholesale-price and revenue-sharing contracts in assembly systems with random demand. Giannoccaro and Pontrandolfo [13] provided a revenue-sharing mechanism to coordinate a three-stage supply chain. Zou et al. [14] proposed a model to synchronize the assembly process in a twoechelon system with stochastic demand and deterministic order processing times. Their study found that a revenuesharing contact through proper safety stock placement could make the supply chain coordination much better. Cachon and Lariviere [10] demonstrated that revenue-sharing contracts can coordinate the supply chain with both a single retailer and competing retailers. Comparing revenue-sharing with other contacts, they found that revenue-sharing is the same as buyback in the newsvendor case and is equivalent to price discount in the price-setting newsvendor. Koulamas [11] studied a one-manufacturer-one-retailer supply chain and compared the expected profits which are received from the traditional ordering case and the revenue-sharing contract. Linh and Hong [15] studied supply chain coordination through revenue-sharing contract between one wholesaler and one retailer in a two-period newsboy environment. They also discussed a single-buying-opportunity model and a two-buyingopportunity model. Xu et al. [16] studied two-stage fashion supply chain coordination with risk-averse retailer and pricedependent demand by use of revenue-sharing contract, twopart tariff contract, and combined contracts. Palsule-Desai [17] designed a game model for revenue-dependent revenuesharing contracts with the actual proportions, and their supply revenues which were shared among the players in each period depend on the actual revenue generated. Hsueh [18] proposed a new revenue-sharing contract embedding corporate social responsibility to coordinate a two-tier supply chain. Sang [19] investigated return contract and revenuesharing contract with one supplier and multiple competing retailers in a fuzzy demand environment and proposed their optimal policies. Xu et al. [20] presented an analytical framework for price decisions in both a centralized and decentralized dual-channel supply chain with risk aversion and proposed the two-way revenue-sharing contract to achieve supply chain coordination. Govindan and Popiuc [21] proposed an analytical model of revenue-sharing contract for the two- and three-echelon reverse supply chain and took the personal computers industry as an example. Feng et al. [22] studied a revenue-sharing contract with reliability in an $\mathrm{N}$ stage supply chain and compared it with common revenuesharing contract.

Disruption management in supply chain is the most closely related research to our work. Qi et al. [1] introduced the idea of disruption management into supply chain coordination management. They first investigated that disruptions led to deviation penalties for the original production quantity change and coordinated the supply chain with one supplier and one retailer by wholesale quantity discount policies after demand disruptions. Xiao et al. [2] extended the model into the supply chain including two competing retailers with sales promotion opportunities. They proposed a price-subsidy rate contract to coordinate promotion investment and demand disruptions. Based on this supply chain, Xiao and Qi [5] added cost disruption into previous issues and studied the supply chain coordination by an all-unit quantity discount scheme and an incremental quantity discount scheme. Zhang et al. [3] investigated how to coordinate supply chain with one manufacture and two peer retailers under demand disruptions by revenue-sharing contracts. However, Xiao et al. [6] considered that the production deviation cost was borne by the manufacturer or the retailers and studied the coordination mechanism by either a linear quantity discount schedule or an all-unit quantity discount schedule when demand is disrupted. Huang et al. [23] developed a two-period pricing and production decision model in a one-manufacturer-oneretailer dual-channel supply chain with demand disruptions. Lei et al. [24] studied the risk management strategies in supply chain with one supplier and one retailer under demand disruptions and cost disruptions with asymmetric information. They utilized linear contract menus to analyze this issue. He and Wang [25] investigated production-inventory system for deteriorating items with demand disruptions and derived the optimal production run time and replenishment policy for spot market purchase in different scenarios. Cao et al. [26] developed a coordination mechanism with revenuesharing contract when the production cost and demand were simultaneously disrupted and their supply chain included one manufacturer and $n$ Cournot competing retailers. X. Wang and Y. Wang [27] constructed a game model to coordinate the two-echelon closed-loop supply chain with one manufacturer and one retailer. They considered the market scale, reproduction cost, and recovery price sensitivity coefficient are disrupted simultaneously when abrupt incident occurred. Tavakoli and Mirzaee [28] investigated the coordination of a three-level supply chain with one manufacturer, one distributer, and one retailer under demand disruptions by revenue-sharing and return policy contracts.

Meanwhile, the retail trade market today is increasingly dominated by large, centrally managed "power retailers" [4]. Their study showed that service investment can mete out minimum incentive for the manufacturer to engage the 
dominant retailer in supply chain coordination. Geylani et al. [29] presented a theoretical model to illustrate a strategic manufacturer response to a dominant retailer. In their model, the dominant retailer could determine his own wholesale price, but the manufacturer set the wholesale price for the fringe retailers. Chen and Xiao [7] designed the supply chain coordination mechanism with one manufacturer, one dominant retailer, and multiple fringe retailers after demand disruptions. They considered linear quantity schedule and Groves wholesale price schedule. Chen and Zhuang [30] continued studying this problem under linear quantity discount scheme, but the increased demand and the cost by demandstimulating service are independent, while the former is a function of [7].

There are several differences between our model and previous papers. Above all, we study how to coordinate a onemanufacturer multi-retailers supply chain with a dominant retailer by revenue-sharing contracts after demand disruptions for the first time. We fully consider the impact of a dominant retailer on the market retail price and his sales promotion opportunity. The dominant retailer is implicitly recognized as the leader, while the other fringe retailers are considered as the price followers. Secondly, previous papers only discuss the case in which the market scale changes when demand is disrupted. In this paper, we considered both the market scale and price sensitive coefficient are disrupted simultaneously.

\section{The Basic Model}

In this section, we investigate a supply chain model with one manufacturer selling products through a dominant retailer and $N$ fringe retailers, where $N \geq 2$. We assume the dominant retailer has market power and determines the retail price. Once the price is settled down, all fringe retailers regard it as the market retail price, which is generally consistent with the marketing operation described earlier, where some small retailers use the pricing book of a large retailer. For instance, Wal-Mart can be regarded as a dominant retailer because the proportion of its sales makes up 39\% of Tandy's total sales and $17 \%$ of P\&G's in 2002 [31]. Another example is the US automobile industry, where General Motors has traditionally been the price leader [32]. Moreover, only the dominant retailer can provide the demand-stimulating service to the manufacturer's products [4]. For instance, the dominant retailer can carry on some propagating advertisement to promote the production.

Similar to Chen and Xiao [7], we assume that the total market demand is

$$
q_{T}=\alpha-\beta p+\theta \sqrt{s}
$$

Here, $\alpha$ represents the total market scale and $\beta$ is the price sensitive coefficient $(\alpha, \beta>0)$. The service cost of the dominant retailer is $s$, which could be opportunity cost. $\theta$ is the demand sensitivity to $s, \theta \in(0,2 \sqrt{\beta})$. To ensure that the order quantity is nonnegative, we assume $\alpha+\theta \sqrt{s}>\beta p$.

Therefore, the market demand for the dominant retailer is $q_{d}=\gamma q_{T}$, where $\gamma \leq 1$ is the fraction of the market demand which the dominant retailer accounted for. Meanwhile, the demand, which is shared by the $N$ fringe retailers in our assumption, is $q_{r}=(1-\gamma) q_{T}$ as a whole.

Commonly, the contracts have been proven to be effective in improving supply chain performance. At the same time, each of the chain partners can earn more profit than that they could attain without revenue-sharing contract [13].

In the centralized supply chain, the total profit is

$$
T=\left(p-c_{1}-c_{0}\right) q_{T}-s .
$$

Here, the manufacturer produces products with a unit cost $c_{0}$ and sells to the retailer $i$ at a unit price $w_{i}(i=d, r)$. After purchasing the products from the manufacturer, the retailers add some values to them with a unit cost $c_{1}$. In our study, we assume both dominant and fringe retailers pay the same unit cost.

The profit function of the dominant retailer is

$$
\pi_{d}=\left[\varphi_{d} p-\left(w_{d}+c_{1}\right)\right] q_{d}-t s .
$$

Here, $\varphi_{d}$ is the revenue share of the dominant retailer $\left(0<\varphi_{d}<1\right)$ and $t$ is the fraction of service cost that the dominant retailer bears. As the authors in $[4,33]$ said, $\varphi_{d}$ and $t$ are similar but not identical.

The profit function of the fringe retailer is

$$
\pi_{r}=\left[\varphi_{r} p-\left(w_{r}+c_{1}\right)\right] q_{r}
$$

where $\varphi_{r}$ is the revenue share of the fringe retailer $\left(0<\varphi_{r}<\right.$ 1) and $\varphi_{i} p \geq w_{i}+c_{1}(i=d, r)$.

The profit function of the manufacturer is

$$
\begin{aligned}
\pi_{m}= & {\left[w_{d}-c_{0}+\left(1-\varphi_{d}\right) p\right] q_{d} } \\
& +\left[w_{r}-c_{0}+\left(1-\varphi_{r}\right) p\right] q_{r}-(1-t) s .
\end{aligned}
$$

From (2), we can obtain the optimal retail price and service level in the centralized supply chain:

$$
\begin{aligned}
& p^{*}=\frac{2 \alpha+\left(2 \beta-\theta^{2}\right)\left(c_{0}+c_{1}\right)}{4 \beta-\theta^{2}}, \\
& s^{*}=\frac{\theta^{2}\left[\alpha-\beta\left(c_{0}+c_{1}\right)\right]^{2}}{\left(4 \beta-\theta^{2}\right)^{2}} .
\end{aligned}
$$

The corresponding optimal total order quantity is

$$
q_{T}^{*}=\frac{2 \beta\left[\alpha-\beta\left(c_{0}+c_{1}\right)\right]}{4 \beta-\theta^{2}} .
$$

For convenience, we make the following assumption.

Assumption 1. The market share $(\gamma)$ of the dominant retailer satisfies $1 /\left(2-\left(\theta^{2} / 4 \beta\right)\right)<\gamma<1$.

This implies that $\gamma\left[p^{*}-\left(c_{0}+c_{1}\right)\right]\left(\alpha-\beta p^{*}+\theta \sqrt{s^{*}}\right)-s^{*}>$ $\max _{p} \gamma\left[p-\left(c_{0}+c_{1}\right)\right](\alpha-\beta p)$. The above inequality means the market share of the dominant retailer is too large for the dominant retailer to provide the demand-stimulating service 
voluntarily, and the manufacturer would like to induce such service even when the supply chain is in the decentralized operation. The magnitude of $\gamma$ indicates that the dominant retailer has market power absolutely and can decide the retail price and demand-stimulating service level.

In the decentralized supply chain, the dominant retailer determines the retail price to maximize his own profit. Solving the first-order conditions of (3) with respect to $p$ and $s$, we can obtain

$$
\begin{aligned}
& p_{d}^{\Delta}=\frac{2 t \varphi_{d} \alpha+\left(2 t \beta-\gamma \theta^{2} \varphi_{d}\right)\left(w_{d}+c_{1}\right)}{4 t \varphi_{d} \beta-\gamma \theta^{2} \varphi_{d}^{2}}, \\
& s_{d}^{\Delta}=\frac{\gamma^{2} \theta^{2}\left[\varphi_{d} \alpha-\beta\left(w_{d}+c_{1}\right)\right]^{2}}{\left(4 t \beta-\gamma \theta^{2} \varphi_{d}\right)^{2}} .
\end{aligned}
$$

Let $p_{d}^{\Delta}=p^{*}$ and $s_{d}^{\Delta}=s^{*}$ and we have

$$
\begin{gathered}
w_{d}^{*}=\frac{\varphi_{d}^{*}}{\beta}\left(-\alpha+2 \beta p^{*}-\theta \sqrt{s^{*}}\right)-c_{1}, \\
t^{*}=\frac{\gamma \theta \varphi_{d}^{*}}{2 \beta \sqrt{s^{*}}}\left(\alpha-\beta p^{*}+\theta \sqrt{s^{*}}\right)=\gamma \varphi_{d}^{*} .
\end{gathered}
$$

Here, $4 t^{*} \beta-\gamma \theta^{2} \varphi_{d}^{*}>0$. The function of $t^{*}$ implies that the higher market share of the dominant retailer is, the smaller subsidy is provided by the manufacturer.

In order to take as much profit away from the fringe retailer as possible and eliminate any free-riding on $s$ by fringe retailers, the manufacturer should design wholesale price $w_{r}$ and achieve its maximum profit by setting $\varphi_{r} p^{*}=w_{r}+c_{1}$. It is also common in practice. In some monopoly industries, the leader prevents new partner from entering the market [32]. Similarly, the profit of fringe retailers is much less than that of dominant retailer. Therefore, for the convenience of calculation, we assume $w_{r}^{*}=\varphi_{r}^{*} p^{*}-c_{1}$.

If the system is in the market-like setting without any contracts, it would work as follows. The manufacturer produces the products at a unit cost $c_{0}$ and sells them to retailer $i$ at a unit price $w_{m}$. Based on the market demand and the retail price $p_{m}$, retailer $i$ orders the quantity $q_{i m}(i=d, r)$ and his unit cost is $c_{1}$.

In the market-like setting, the profit function of the dominant retailer is

$$
\pi_{d m}=\left[p_{m}-\left(w_{m}+c_{1}\right)\right] q_{d m}-s_{m} .
$$

The profit function of the fringe retailer is

$$
\pi_{r m}=\left[p_{m}-\left(w_{m}+c_{1}\right)\right] q_{r m} .
$$

The profit function of the manufacturer is

$$
\pi_{m m}=\left(w_{m}-c_{0}\right) q_{T m},
$$

where $q_{T m}=\alpha-\beta p_{m}+\theta \sqrt{s_{m}}, q_{d m}=\gamma q_{T m}$, and $q_{r m}=(1-$ $\gamma) q_{\text {Tm }}$.

The total profit of the supply chain in the market-like setting is

$$
T_{m}=\left[p_{m}-\left(c_{0}+c_{1}\right)\right] q_{T m}-s_{m}
$$

By solving the first-order condition $\partial \pi_{d m} / \partial p_{m}=0$ and $\partial \pi_{d m} / \partial s_{m}=0$, we can obtain the optimal retail price in the market-like setting given by

$$
\begin{aligned}
& p_{m}=\frac{2 \alpha+\left(2 \beta-\gamma \theta^{2}\right)\left(w_{m}+c_{1}\right)}{4 \beta-\gamma \theta^{2}}, \\
& s_{m}=\frac{\gamma^{2} \theta^{2}\left[\alpha-\beta\left(w_{m}+c_{1}\right)\right]^{2}}{\left(4 \beta-\gamma \theta^{2}\right)^{2}} .
\end{aligned}
$$

By substituting (14) into (12) and solving the first-order conditions of (12) with respect to $w_{m}$, we have

$$
w_{m}^{*}=\frac{\alpha+\beta\left(c_{0}-c_{1}\right)}{2 \beta} .
$$

The optimal retail price $p_{m}^{*}$ and the corresponding optimal service level $s_{m}^{*}$ in the market-like setting are

$$
\begin{aligned}
& p_{m}^{*}=\frac{4 \alpha \beta+\left(2 \beta-\gamma \theta^{2}\right)\left[\alpha+\beta\left(c_{0}+c_{1}\right)\right]}{2 \beta\left(4 \beta-\gamma \theta^{2}\right)}, \\
& s_{m}^{*}=\frac{\gamma^{2} \theta^{2}\left[\alpha-\beta\left(c_{0}+c_{1}\right)\right]^{2}}{4\left(4 \beta-\gamma \theta^{2}\right)^{2}} .
\end{aligned}
$$

Based on the above discussions, we can derive Theorem 2.

Theorem 2. The following revenue-sharing contracts can coordinate the supply chain with one dominant retailer:

$$
\begin{gathered}
w_{d}^{*}=\frac{\varphi_{d}^{*}}{\beta}\left(-\alpha+2 \beta p^{*}-\theta \sqrt{s^{*}}\right)-c_{1}, \\
t^{*}=\frac{\gamma \theta \varphi_{d}^{*}}{2 \beta \sqrt{s^{*}}}\left(\alpha-\beta p^{*}+\theta \sqrt{s^{*}}\right), \\
w_{r}^{*}=\varphi_{r}^{*} p^{*}-c_{1}, \\
\underline{\varphi_{d}}<\varphi_{d}^{*}<\overline{\varphi_{d}}
\end{gathered}
$$

where

$$
\begin{gathered}
\underline{\varphi_{d}}=\max \left\{\frac{\beta c_{1}}{\beta p^{*}-q_{T}^{*}}, \frac{2 \beta\left\{\left[p_{m}^{*}-\left(w_{m}^{*}+c_{1}\right)\right] q_{d m}^{*}-s_{m}^{*}\right\}}{q_{T}^{*}\left(2 q_{d}^{*}-\gamma \theta \sqrt{s^{*}}\right)}\right\}, \\
\overline{\varphi_{d}}=\min \left\{\frac{2 \beta\left[\left(p^{*}-c_{1}-c_{0}\right) q_{T}^{*}-\left(w_{m}^{*}-c_{0}\right) q_{T m}^{*}-s^{*}\right]}{q_{T}^{*}\left(2 q_{d}^{*}-\gamma \theta \sqrt{s^{*}}\right)}, 1\right\} .
\end{gathered}
$$

Proof. In order to coordinate the supply chain, the revenuesharing contracts have to be designed such that $p_{d}^{\Delta}=p^{*}, s_{d}^{\Delta}=$ $s^{*}$, and $\varphi_{r} p^{*}=w_{r}+c_{1}$. We get (17) and (18).

Since $0<\varphi_{d}^{*}<1$ and $w_{d}^{*}>0$, the dominant retailer's revenue share satisfies

$$
\frac{\beta c_{1}}{\beta p^{*}-q_{T}^{*}}<\varphi_{d}^{*}<1 .
$$


Then, we will further analyze how the contract can be designed to satisfy win-win condition for the chain partners. Assume that $\pi_{k}^{*}$ is the optimal profit of the actor $k(k=$ $m, d)$ in the supply chain with the revenue-sharing contracts and $\pi_{k m}^{*}$ is the optimal profit of the actor $k(k=m, d)$ in the market-like setting. We know that the revenue-sharing contracts are acceptable to the chain partners only $\pi_{k}^{*}>\pi_{k m}^{*}$. Then we have

$$
\begin{gathered}
{\left[\varphi_{d}^{*} p^{*}-\left(w_{d}^{*}+c_{1}\right)\right] q_{d}^{*}-t^{*} s^{*}>\left[p_{m}^{*}-\left(w_{m}^{*}+c_{1}\right)\right] q_{d m}^{*}-s_{m}^{*},} \\
{\left[w_{d}^{*}-c_{0}+\left(1-\varphi_{d}^{*}\right) p^{*}\right] q_{d}^{*}+\left[w_{r}^{*}-c_{0}+\left(1-\varphi_{r}^{*}\right) p^{*}\right] q_{r}^{*}} \\
-\left(1-t^{*}\right) s^{*}>\left(w_{m}^{*}-c_{0}\right) q_{T m}^{*} .
\end{gathered}
$$

By substituting (14) and (17) into (22), we can obtain

$$
\begin{gathered}
\varphi_{d}^{*}>\frac{2 \beta\left\{\left[p_{m}^{*}-\left(w_{m}^{*}+c_{1}\right)\right] q_{d m}^{*}-s_{m}^{*}\right\}}{q_{T}^{*}\left(2 q_{d}^{*}-\gamma \theta \sqrt{s^{*}}\right)}, \\
\varphi_{d}^{*}<\frac{2 \beta\left[\left(p^{*}-c_{1}-c_{0}\right) q_{T}^{*}-\left(w_{m}^{*}-c_{0}\right) q_{T m}^{*}-s^{*}\right]}{q_{T}^{*}\left(2 q_{d}^{*}-\gamma \theta \sqrt{s^{*}}\right)} .
\end{gathered}
$$

Equation (19) is directly obtained by (21) and (23).

Based the above discussion, we can see that if the revenuesharing contracts satisfy Theorem 2 , the supply chain can be coordinated under normal operation without demand disruption.

\section{Supply Chain Coordination under Demand Disruptions}

When the demand is disrupted, the original scheme may become invalid. In our model, we utilize the changes of the market scale and price sensitive coefficient to indicate demand disruptions. In this section, we will investigate supply chain coordination mechanism with revenue-sharing contract under demand disruptions. For clear expression, we use the notation with a tilde $(\sim)$ to denote this case. Demand disruptions often lead to certain extra deviation costs associated with the total production deviation quantity. As used in $[1,2,7]$, we assumed the deviation costs are incurred to the manufacturer, since it often employs a return policy for the unsold products and provide more for the increased demand.

In this section, we assume that the market scale $\alpha$ is changed into $\widetilde{\alpha}=\alpha+\Delta \alpha>0$ and the price sensitive coefficient $\beta$ is changed into $\widetilde{\beta}=\beta+\Delta \beta>0$, where $\Delta \alpha$ and $\Delta \beta$ are the shock to the market demand with $\Delta \alpha>-\alpha$ and $\Delta \beta>-\beta . \Delta \alpha>0$ represents an increased demand scale, while $\Delta \alpha<0$ represents a decreased demand scale. $\Delta \alpha$ and $\Delta \beta$ are independent of the demand-stimulating service. Then, the total demand function can be denoted by $\widetilde{q}_{T}=\widetilde{\alpha}-\widetilde{\beta} \tilde{p}+\theta \sqrt{\widetilde{s}}$.

The total production deviation quantity is

$$
\Delta \widetilde{Q}=\widetilde{q}_{T}-q_{T}^{*}=\alpha+\Delta \alpha-(\beta+\Delta \beta) \widetilde{p}+\theta \sqrt{\widetilde{s}}-q_{T}^{*} .
$$

If $\Delta Q>0$, the manufacturer needs to produce more products to meet the unplanned increased market demand, which will cause an extra cost in machines, labor input, and raw materials. If $\Delta Q<0$, there are some extra holding costs that result from an excess supply which generate some leftover inventory. As used in $[1,5]$, we define a unit penalty $\operatorname{cost} c_{u} \geq 0$ for the increased production and similarly a unit penalty $\operatorname{cost} c_{s} \geq 0$ for the decreased production.

The total profit of the centralized supply chain is

$$
\widetilde{T}=\left(\widetilde{p}-c_{1}-c_{0}\right) \tilde{q}_{T}-\widetilde{s}-c_{u}(\Delta \widetilde{Q})^{+}-c_{s}(-\Delta \widetilde{Q})^{+}
$$

From Assumption 1, we can see that when the price sensitive coefficient $(\beta)$ changes, the market share $(\gamma)$ of the dominant retailer should adjust to satisfy $1 /\left(2-\theta^{2} /(4 \widetilde{\beta})\right)<$ $\gamma<1$.

By solving the Kuhn-Tucker conditions of (25), we can obtain the following results.

Corollary 3. When demand disruptions occur, the optimal retail price and service levels in the centralized supply chain are as follows.

(1) If $\left(2 \widetilde{\alpha} \widetilde{\beta}-2 \widetilde{\beta}^{2}\left(c_{0}+c_{1}\right)-\left(4 \widetilde{\beta}-\theta^{2}\right) q_{T}^{*}\right) / 2 \widetilde{\beta}^{2} \geq c_{u}$, then

$$
\begin{gathered}
\tilde{p}_{1}^{*}=\frac{2 \widetilde{\alpha}+\left(2 \widetilde{\beta}-\theta^{2}\right)\left(c_{0}+c_{1}+c_{u}\right)}{4 \widetilde{\beta}-\theta^{2}}, \\
\widetilde{s}_{1}^{*}=\frac{\theta^{2}\left[\widetilde{\alpha}-\widetilde{\beta}\left(c_{0}+c_{1}+c_{u}\right)\right]^{2}}{\left(4 \widetilde{\beta}-\theta^{2}\right)^{2}} .
\end{gathered}
$$

(2) If $-c_{s}<\left(2 \widetilde{\alpha} \widetilde{\beta}-2 \widetilde{\beta}^{2}\left(c_{0}+c_{1}\right)-\left(4 \widetilde{\beta}-\theta^{2}\right) q_{T}^{*}\right) / 2 \widetilde{\beta}^{2}<c_{u}$, then

$$
\tilde{p}_{2}^{*}=\frac{\beta^{2}\left(2 \widetilde{\beta}-\theta^{2}\right)}{\widetilde{\beta}^{2}\left(2 \beta-\theta^{2}\right)}\left(\beta p^{*}-\alpha\right)+\frac{\widetilde{\alpha}}{\widetilde{\beta}}, \quad \widetilde{s}_{2}^{*}=\frac{\beta^{2}}{\widetilde{\beta}^{2}} s^{*} .
$$

(3) If $\left(2 \tilde{\alpha} \widetilde{\beta}-2 \widetilde{\beta}^{2}\left(c_{0}+c_{1}\right)-\left(4 \widetilde{\beta}-\theta^{2}\right) q_{T}^{*}\right) / 2 \widetilde{\beta}^{2} \leq-c_{s}$, then

$$
\begin{gathered}
\widetilde{p}_{3}^{*}=\frac{2 \widetilde{\alpha}+\left(2 \widetilde{\beta}-\theta^{2}\right)\left(c_{0}+c_{1}-c_{s}\right)}{4 \widetilde{\beta}-\theta^{2}}, \\
\widetilde{s}_{3}^{*}=\frac{\theta^{2}\left[\tilde{\alpha}-\tilde{\beta}\left(c_{0}+c_{1}-c_{s}\right)\right]^{2}}{\left(4 \widetilde{\beta}-\theta^{2}\right)^{2}} .
\end{gathered}
$$

From Corollary 3, we know that it is optimal for the supply chain to keep the original quantity if the changed amount is sufficiently small. Hence, the supply chain should keep the original quantity to avoid the production deviation cost and change the original retail price to offset the effect of the demand disruptions. If the changed amount is large, the manufacturer should change the production quantity to satisfy the new market demand. 
In a decentralized supply chain, we know that the profit functions of the dominant and fringe retailers and the manufacturer are

$$
\begin{aligned}
\tilde{\pi}_{d}= & {\left[\widetilde{\varphi}_{d} \tilde{p}-\left(\widetilde{w}_{d}+c_{1}\right)\right] \widetilde{q}_{d}-\widetilde{t} \widetilde{s} } \\
\tilde{\pi}_{r}= & {\left[\widetilde{\varphi}_{r} p-\left(\widetilde{w}_{r}+c_{1}\right)\right] \widetilde{q}_{r}, } \\
\tilde{\pi}_{m}= & {\left[\widetilde{w}_{d}-c_{0}+\left(1-\widetilde{\varphi}_{d}\right) \widetilde{p}\right] \tilde{q}_{d}+\left[\widetilde{w}_{r}-c_{0}+\left(1-\widetilde{\varphi}_{r}\right) \widetilde{p}\right] \tilde{q}_{r} } \\
& -(1-\tilde{t}) \widetilde{s}-c_{u}(\Delta \widetilde{Q})^{+}-c_{s}(-\Delta \widetilde{Q})^{+} .
\end{aligned}
$$

Solving the first-order condition of $\tilde{\pi}_{d}$, we have

$$
\begin{aligned}
& \widetilde{p}_{d}^{\Delta}=\frac{2 \widetilde{t} \widetilde{\varphi}_{d} \tilde{\alpha}+\left(2 \tilde{t} \tilde{\beta}-\gamma \theta^{2} \widetilde{\varphi}_{d}\right)\left(\widetilde{w}_{d}+c_{1}\right)}{4 \widetilde{t} \widetilde{\varphi}_{d} \widetilde{\beta}-\gamma \theta^{2} \widetilde{\varphi}_{d}^{2}}, \\
& \widetilde{s}_{d}^{\Delta}=\frac{\gamma^{2} \theta^{2}\left[\widetilde{\varphi}_{d} \tilde{\alpha}-\tilde{\beta}\left(\widetilde{w}_{d}+c_{1}\right)\right]^{2}}{\left(4 \tilde{t} \tilde{\beta}-\gamma \theta^{2} \widetilde{\varphi}_{d}\right)^{2}} .
\end{aligned}
$$

In order to coordinate the decentralized system, let $\widetilde{p}_{d}^{\Delta}=$ $\widetilde{p}_{i}^{*}$ and $\widetilde{s}_{d}^{\Delta}=\widetilde{s}_{i}^{*}, i=1,2,3$. Similar to the previous analysis, the manufacturer should design wholesale price of fringe retailer $\widetilde{w}_{r}$ to achieve its maximum profit by setting $\widetilde{\varphi}_{r}^{*} \widetilde{p}^{*}=\widetilde{w}_{r}^{*}+c_{1}$. So we can obtain

$$
\begin{gathered}
\widetilde{w}_{d}^{*}=\frac{\tilde{\varphi}_{d}^{*}}{\widetilde{\beta}}\left(-\widetilde{\alpha}+2 \widetilde{\beta} \widetilde{p}^{*}-\theta \sqrt{\widetilde{s}^{*}}\right)-c_{1}, \\
\widetilde{w}_{r}^{*}=\widetilde{\varphi}_{r}^{*} \widetilde{p}^{*}-c_{1}, \\
\widetilde{t}^{*}=\frac{\gamma \theta \widetilde{\varphi}_{d}^{*}}{2 \widetilde{\beta} \sqrt{\widetilde{s}^{*}}}\left(\widetilde{\alpha}+\theta \sqrt{\widetilde{s}^{*}}-\tilde{\beta} \widetilde{p}^{*}\right) .
\end{gathered}
$$

To illustrate the desirability and effectiveness of the new revenue-sharing contracts, we study the case when the partners do not make measures to the demand disruptions and keep the original schemes: the dominant retailer keeps the optimal retail price $p^{*}$ and service $s^{*}$ and the unit cost is $c_{1}$; the manufacturer keeps the contract $\left(w_{i}^{*}, \varphi_{i}^{*}\right)$ without demand disruptions and his production cost is still $c_{0}$. Then the real total market demand is $\widetilde{q}_{T r}^{*}=\widetilde{\alpha}-\widetilde{\beta} p^{*}+\theta \sqrt{s^{*}}$.

The market demand for a dominant retailer is $\tilde{q}_{d r}^{*}=\gamma \tilde{q}_{T r}^{*}$ and fringe retailer is $\widetilde{q}_{r r}^{*}=(1-\gamma) \widetilde{q}_{T r}^{*}$.

The profit functions of the retailers and the manufacturer in this setting are

$$
\begin{gathered}
\tilde{\pi}_{d r}=\left[\varphi_{d}^{*} p^{*}-\left(w_{d}^{*}+c_{1}\right)\right] \tilde{q}_{d r}^{*}-t^{*} s^{*}, \\
\tilde{\pi}_{r r}=\left[\varphi_{r}^{*} p^{*}-\left(w_{r}^{*}+c_{1}\right)\right] \widetilde{q}_{r r}^{*}, \\
\tilde{\pi}_{m r}=\left[w_{d}^{*}-c_{0}+\left(1-\varphi_{d}^{*}\right) p^{*}\right] \widetilde{q}_{d r}^{*} \\
+\left[w_{r}^{*}-c_{0}+\left(1-\varphi_{r}^{*}\right) p^{*}\right] \widetilde{q}_{r r}^{*}-\left(1-t^{*}\right) s^{*} \\
-c_{u}\left(\Delta \widetilde{Q}_{r}\right)^{+}-c_{s}\left(-\Delta \widetilde{Q}_{r}\right)^{+} .
\end{gathered}
$$

Here, $\Delta \widetilde{Q}_{r}=\widetilde{q}_{T r}^{*}-q_{T}^{*}$.
The total profit of the supply chain in the setting is

$\widetilde{T}_{r}=\left(p^{*}-c_{1}-c_{0}\right) \widetilde{q}_{T r}^{*}-s^{*}-c_{u}\left(\Delta \widetilde{Q}_{r}\right)^{+}-c_{s}\left(-\Delta \widetilde{Q}_{r}\right)^{+}$.

According to the above descriptions, we can derive Theorem 4.

Theorem 4. If demand disruptions occur, the following revenue-sharing contracts can coordinate the supply chain with one dominant retailer:

$$
\begin{gathered}
\widetilde{w}_{d}^{*}=\frac{\tilde{\varphi}_{d}^{*}}{\widetilde{\beta}}\left(-\tilde{\alpha}+2 \widetilde{\beta} \widetilde{p}^{*}-\theta \sqrt{\widetilde{s}^{*}}\right)-c_{1}, \\
\widetilde{t}^{*}=\frac{\gamma \theta \widetilde{\varphi}_{d}^{*}}{2 \widetilde{\beta} \sqrt{\widetilde{s}^{*}}}\left(\widetilde{\alpha}+\theta \sqrt{\widetilde{s}^{*}}-\widetilde{\beta} \widetilde{p}^{*}\right), \\
\widetilde{w}_{r}^{*}=\widetilde{\varphi}_{r}^{*} \widetilde{p}^{*}-c_{1}, \\
\underline{\tilde{\varphi}}_{d}<\widetilde{\varphi}_{d}^{*}<\overline{\widetilde{\varphi}_{d}},
\end{gathered}
$$

where

$$
\begin{aligned}
& \underline{\tilde{\varphi}_{d}}=\max \left\{\frac{\widetilde{\beta} c_{1}}{\widetilde{\beta} \widetilde{p}^{*}-\widetilde{q}_{T}^{*}},\right. \\
& \left.\frac{2 \widetilde{\beta}\left\{\left[\varphi_{d}^{*} p^{*}-\left(w_{d}^{*}+c_{1}\right)\right] \tilde{q}_{d r}^{*}-t^{*} s^{*}\right\}}{\widetilde{q}_{T}^{*}\left(2 \widetilde{q}_{d}^{*}-\gamma \theta \sqrt{\widetilde{s}^{*}}\right)}\right\}, \\
& \overline{\widetilde{\varphi}_{d}}=\min \left\{\frac{2 \widetilde{\beta}\left(\widetilde{T}^{*}-\tilde{\pi}_{m r}\right)}{\tilde{q}_{T}^{*}\left(2 \widetilde{q}_{d}^{*}-\gamma \theta \sqrt{\widetilde{s}^{*}}\right)}, 1\right\} .
\end{aligned}
$$

Proof. Because $0<\widetilde{\varphi}_{d}^{*}<1$ and $\widetilde{w}_{d}^{*}>0$, $\widetilde{\varphi}_{d}^{*}$ satisfies

$$
\frac{\tilde{\beta} c_{1}}{\widetilde{\beta} \tilde{p}^{*}-\tilde{q}_{T}^{*}}<\widetilde{\varphi}_{d}^{*}<1 .
$$

Assume that $\tilde{\pi}_{k}^{*}$ and $\tilde{\pi}_{k r}$, respectively, denote the optimal profit of the actor $k(k=d, m)$ in the supply chain with the new and original revenue-sharing contracts. In order to assure the desirability and effectiveness of the new revenuesharing contracts by the chain partners, $\tilde{\pi}_{k}^{*}$ should be higher than $\widetilde{\pi}_{k r}$. So we can obtain

$$
\begin{aligned}
& {\left[\widetilde{\varphi}_{d}^{*} \widetilde{p}^{*}-\left(\widetilde{w}_{d}^{*}+c_{1}\right)\right] \widetilde{q}_{d}^{*}-\widetilde{t}^{*} \widetilde{s}^{*}} \\
& \quad>\left[\varphi_{d}^{*} p^{*}-\left(w_{d}^{*}+c_{1}\right)\right] \widetilde{q}_{d r}^{*}-t^{*} s^{*}, \\
& {\left[\widetilde{w}_{d}^{*}-c_{0}+\left(1-\widetilde{\varphi}_{d}^{*}\right) \widetilde{p}^{*}\right] \widetilde{q}_{d}^{*}+\left[\widetilde{w}_{r}^{*}-c_{0}+\left(1-\widetilde{\varphi}_{r}^{*}\right) \widetilde{p}^{*}\right] \widetilde{q}_{r}^{*}} \\
& \quad-\left(1-\widetilde{t}^{*}\right) \widetilde{s}^{*}-c_{u}(\Delta \widetilde{Q})^{+}-c_{s}(-\Delta \widetilde{Q})^{+}>\widetilde{\pi}_{m r} .
\end{aligned}
$$

Substituting (34) into (39), we can obtain

$$
\begin{aligned}
& \widetilde{\varphi}_{d}^{*}>\frac{2 \widetilde{\beta}\left\{\left[\varphi_{d}^{*} p^{*}-\left(w_{d}^{*}+c_{1}\right)\right] \widetilde{q}_{d r}^{*}-t^{*} s^{*}\right\}}{\tilde{q}_{T}^{*}\left(2 \widetilde{q}_{d}^{*}-\gamma \theta \sqrt{\widetilde{s}^{*}}\right)}, \\
& \tilde{\varphi}_{d}^{*}<\frac{2 \widetilde{\beta}\left(\widetilde{T}^{*}-\tilde{\pi}_{m r}\right)}{\widetilde{q}_{T}^{*}\left(2 \widetilde{q}_{d}^{*}-\gamma \theta \sqrt{\widetilde{s}^{*}}\right)} .
\end{aligned}
$$


TABle 1: Parameters under revenue-sharing contracts.

\begin{tabular}{cccccccccc}
\hline$p^{*}$ & $s^{*}$ & $q_{T}^{*}$ & $q_{d}^{*}$ & $q_{r}^{*}$ & $t^{*}$ & $w_{d}^{*}$ & $\pi_{d}^{*}$ & $\pi_{m}^{*}$ & $T^{*}$ \\
\hline 13 & 4 & 8 & 5.6 & 2.4 & 0.315 & 1.25 & 18.9 & 41.1 & 60 \\
\hline
\end{tabular}

TABle 2: Parameters in the market-like setting.

\begin{tabular}{lccccccccc}
\hline$p_{m}^{*}$ & $s_{m}^{*}$ & $q_{T m}^{*}$ & $q_{d m}^{*}$ & $q_{r m}^{*}$ & $w_{m}^{*}$ & $\pi_{d m}^{*}$ & $\pi_{r m}^{*}$ & $\pi_{m m}^{*}$ & $T_{m}^{*}$ \\
\hline 16.42 & 0.47 & 3.92 & 2.75 & 1.18 & 11.5 & 10.29 & 4.61 & 29.41 & 44.32 \\
\hline
\end{tabular}

Theorem 4 gives the coordination mechanism of the decentralized supply chain with demand disruptions. From Theorem 4, we can find that when the new contract satisfies the conditions of Theorem 4, both the dominant retailer and manufacturer can obtain more profit than keeping the original revenue-sharing contracts in Theorem 2.

\section{Numerical Examples}

In the above sections, we discuss how to design the supply chain coordination mechanism in different scenarios of demand disruptions in theory. In this section, some numerical examples are presented to support our model.

5.1. The Basic Model. First of all, we discuss the revenuesharing contracts without demand disruptions. We assume that the values of basic parameters are $\alpha=20, \beta=1, \gamma=0.7$, $\theta=0.5, c_{0}=4$, and $c_{1}=1$. According to Section 3, we can obtain the optimal retail price, service level, and order quantity. From (19) in Theorem 2, the feasible domain for $\varphi_{d}^{*}$ is $0.2675<\varphi_{d}^{*}<0.5950$, which assures the coordination of supply chain. Therefore, suppose $\varphi_{d}^{*}=0.45$. Then we can obtain the associated parameters under revenue-sharing contracts in Table 1. In order to illustrate the efficiency of the revenue-sharing contracts, the associated parameters without any contracts are shown in Table 2. Tables 1 and 2 show that the profit of supply chain increases obviously when the supply chain is coordinated by the revenue-sharing contracts. Meanwhile, the dominant retailer and manufacturer can both obtain more profits than that without any contracts.

\subsection{Supply Chain Coordination under Demand Disruptions.} In Section 4, we study the coordination of supply chain with demand disruptions. Here, we utilize a numerical example to illustrate win-win situation for both the dominant retailer and manufacturer with revenue-sharing contracts. In the following example, we assume $\alpha=20, \beta=1, \gamma=0.7, \theta=0.5$, $c_{0}=4, c_{1}=1$, and $c_{u}=c_{s}=1$.

Firstly, we analyze the relationship between the optimal retail price $\widetilde{p}^{*}$ and order quantity $\widetilde{q}_{T}^{*}$, when the demand is disrupted. We assign five values to the price sensitive coefficient $\beta$. Then, we study the trend of the optimal retail price and order quantity when the market scale $\alpha$ changes continuously, which are shown in Figures 1 and 2. From Figure 2, we find that when the demand is disrupted slightly, the manufacturer does not change the order quantity. Nevertheless, the dominant retailer will adjust his optimal retail

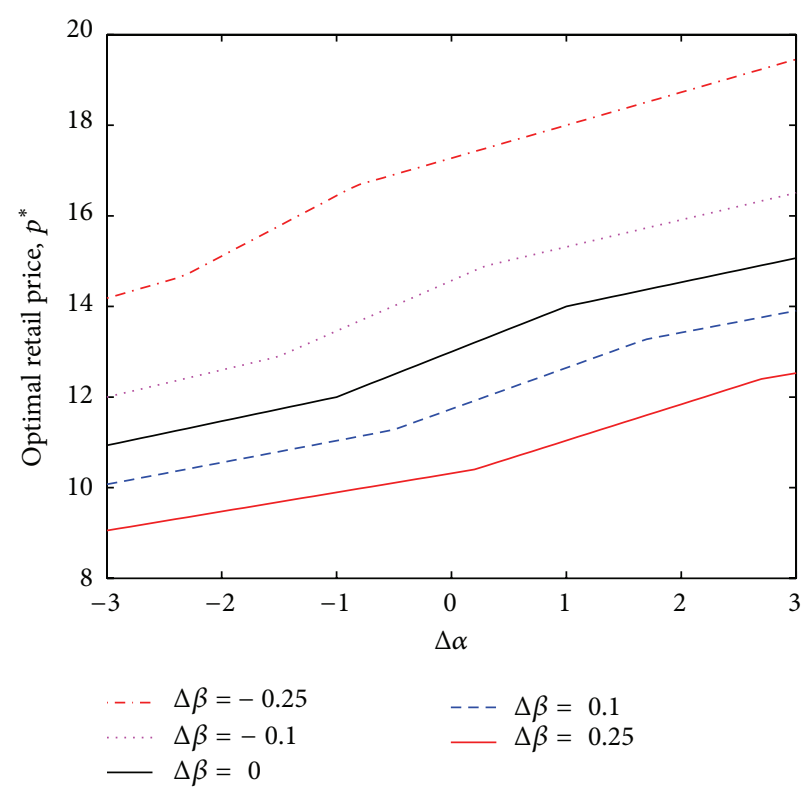

FIGURE 1: Optimal retail price versus demand disruptions.

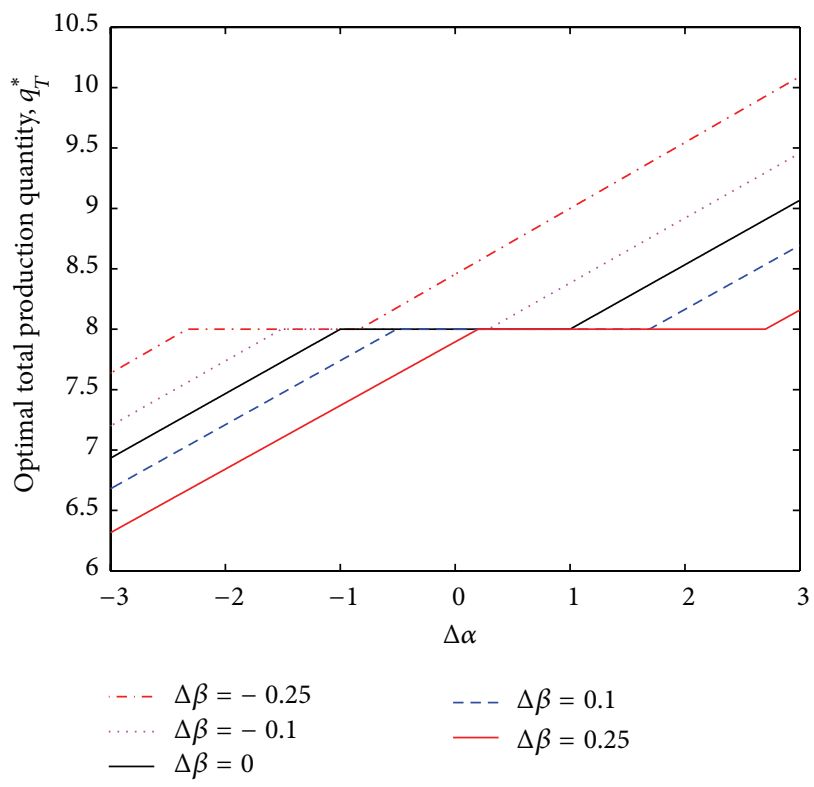

FIGURE 2: Total production quantity versus demand disruptions.

price to decrease the effect of demand disruptions (see Figure 1). However, when demand disruption is sufficiently large, both the optimal retail price and order quantity are strictly increasing with the changed amount of demand even though there are some deviation costs.

Next, we will discuss how the profits change under demand disruptions. Table 3 reveals that the dominant retailer, manufacture, and whole supply chain can benefit from the new coordinating contracts. From Theorem 4, we can obtain the feasible revenue-sharing contracts when demand is disrupted in different cases. In our numerical study, we choose one feasible revenue-sharing contract from 
TABle 3: Parameters under demand disruptions.

\begin{tabular}{|c|c|c|c|c|c|c|c|c|c|c|c|c|c|c|c|c|c|}
\hline Case & $\Delta \alpha$ & $\Delta \beta$ & $\widetilde{p}^{*}$ & $\tilde{s}^{*}$ & $\tilde{q}_{T}^{*}$ & $\tilde{q}_{d}^{*}$ & $\tilde{q}_{r}^{*}$ & $\tilde{\varphi}_{d}^{*}$ & $\tilde{t}^{*}$ & $\widetilde{w}_{d}^{*}$ & $\tilde{\pi}_{d}^{*}$ & $\tilde{\pi}_{m}^{*}$ & $\widetilde{T}^{*}$ & $\tilde{\pi}_{d r}^{*}$ & $\tilde{\pi}_{m r}^{*}$ & $\widetilde{T}_{r}^{*}$ & $\lambda(\%)$ \\
\hline $\mathrm{C} 1$ & 3 & -0.25 & 19.45 & 11.31 & 10.09 & 7.06 & 3.03 & $(0.40,0.73) 0.60$ & 0.42 & 2.60 & 52.27 & 80.18 & 132.45 & 34.65 & 69.1 & 103.75 & 27.66 \\
\hline $\mathrm{C} 2$ & 1 & -0.1 & 15.31 & 5.42 & 8.38 & 5.87 & 2.51 & $(0.49,0.58) 0.55$ & 0.39 & 2.30 & 27.76 & 52.68 & 80.64 & 24.70 & 51.40 & 76.1 & 5.97 \\
\hline $\mathrm{C} 3$ & 1 & 0 & 14 & 4 & 8 & 5.6 & 2.4 & $(0.51,0.53) 0.52$ & 0.36 & 2.12 & 21.84 & 46.16 & 68 & 21.42 & 45.58 & 67 & 1.49 \\
\hline $\mathrm{C} 4$ & -1 & 0 & 12 & 4 & 8 & 5.6 & 2.4 & $(0.39,0.41) 0.40$ & 0.28 & 0.60 & 16.8 & 35.2 & 52 & 16.38 & 34.62 & 51 & 1.49 \\
\hline C5 & -1 & 0.1 & 11.04 & 3.09 & 7.74 & 5.42 & 2.32 & $(0.36,0.48) 0.38$ & 0.27 & 0.52 & 13.66 & 29.70 & 43.36 & 13.10 & 26.20 & 36.45 & 18.96 \\
\hline C6 & -3 & 0.25 & 9.05 & 1.60 & 6.32 & 4.42 & 1.90 & $(0.25,1) 0.60$ & 0.42 & 1.40 & 12.73 & 9.59 & 22.32 & 3.15 & 0.6 & 3.75 & 495.2 \\
\hline
\end{tabular}

each case, in which the optimal revenue share of dominant retailer $\widetilde{\varphi}_{d}^{*}$ is a certain value. Thus, we can calculate the profit in each case and let $\lambda=\left(\widetilde{T}-\widetilde{T}_{r}\right) / \widetilde{T}_{r}$ be the efficiency of the new contract due to disruption management. From Table 3 , we can see that it is harmful for the dominant retailer and manufacture to keep the original revenue-sharing contracts no matter whether the demand is disrupted slightly or largely. The values of $\lambda$ reflect that the effect of proper disruption management is very remarkable. In other words, the stronger demand disruption is, the more profit they can benefit from the new coordination contracts under demand disruptions. Therefore, it is necessary to adjust the original revenuesharing contracts.

\section{Conclusion}

In this paper, we develop a coordination model of a supply chain with one manufacture and multiple retailers, one of which preserves its dominant position in the market. We also investigate how the manufacturer can coordinate such a supply chain by revenue-sharing contracts after demand disruptions. Our study considers the impact of the dominant retailer on the market retail price and his sales promotion opportunity. Firstly, we study an appropriate revenue-sharing contract to coordinate the supply chain without demand disruptions. Then, we fully consider the variations of market scale and price sensitive coefficient and analyze how the demand disruptions affect the coordination mechanism under different scenarios. Finally we conclude that the dominant retailer and manufacture should adjust the original contract to ensure their maximum profits after demand disruptions, especially when the demand changed largely.

For future research, it will be interesting to consider how to coordinate the supply chain by revenue-sharing contracts with asymmetric information. Moreover, it is also interesting to investigate the effect of risk preference on supply chain coordination and design appropriate revenuesharing contracts.

\section{Appendix}

Proof of Corollary 3. For convenience, the objective function (25) can be differentiated into two cases. We can combine these two cases to give the optimal solutions for the centralized supply chain.

$$
\begin{aligned}
& \text { Consider } \\
& \begin{aligned}
& \max _{\widetilde{p}, \widetilde{s}} \widetilde{T}^{1}=\left(\widetilde{p}-c_{1}-c_{0}\right)(\widetilde{\alpha}-\widetilde{\beta} \widetilde{p}+\theta \sqrt{\widetilde{s}})-\widetilde{s}-c_{u} \Delta \widetilde{Q}, \\
& \Delta \widetilde{Q}=\widetilde{\alpha}-\widetilde{\beta} \tilde{p}+\theta \sqrt{\widetilde{s}}-q_{T}^{*} \geq 0, \\
& \max _{\widetilde{p}, \widetilde{s}} \widetilde{T}^{2}=\left(\widetilde{p}-c_{1}-c_{0}\right)(\widetilde{\alpha}-\widetilde{\beta} \tilde{p}+\theta \sqrt{\widetilde{s}})-\widetilde{s}-c_{s} \Delta \widetilde{Q}, \\
& \Delta \widetilde{Q}=\widetilde{\alpha}-\widetilde{\beta} \widetilde{p}+\theta \sqrt{\widetilde{s}}-q_{T}^{*} \leq 0 .
\end{aligned}
\end{aligned}
$$

Based on the above formulas, we can see that $\widetilde{T}^{1}$ and $\widetilde{T}^{2}$ are concave functions of the retail price $\widetilde{p}$ and service investment $\widetilde{s}$; thus, the solutions satisfy the first-order condition when the optimal retail prices and service levels are given.

The Kuhn-Tucker condition of (A.1) is

$$
\begin{gathered}
\frac{\partial \widetilde{T}^{1}}{\partial \tilde{p}}-\lambda \frac{\partial\left(\tilde{\alpha}-\tilde{\beta} \tilde{p}+\theta \sqrt{\widetilde{s}}-q_{T}^{*}\right)}{\partial \widetilde{p}}=0, \\
\frac{\partial \widetilde{T}^{1}}{\partial \widetilde{s}}-\lambda \frac{\partial\left(\tilde{\alpha}-\tilde{\beta} \tilde{p}+\theta \sqrt{\widetilde{s}}-q_{T}^{*}\right)}{\partial \widetilde{s}}=0, \\
\lambda\left(\widetilde{\alpha}-\tilde{\beta} \tilde{p}+\theta \sqrt{\widetilde{s}}-q_{T}^{*}\right)=0, \\
\lambda \geq 0, \\
\tilde{\alpha}-\tilde{\beta} \tilde{p}+\theta \sqrt{\widetilde{s}}-q_{T}^{*} \geq 0,
\end{gathered}
$$

where $\lambda$ is the Lagrangian multiplier. Solving (A.3), we can get the following results.

If $\left(2 \widetilde{\alpha} \widetilde{\beta}-2 \widetilde{\beta}^{2}\left(c_{0}+c_{1}\right)-\left(4 \widetilde{\beta}-\theta^{2}\right) q_{T}^{*}\right) / 2 \widetilde{\beta}^{2} \geq c_{u}$, then the optimal retail price and service level satisfy

$$
\begin{gathered}
\widetilde{p}_{1}^{*}=\frac{2 \widetilde{\alpha}+\left(2 \widetilde{\beta}-\theta^{2}\right)\left(c_{0}+c_{1}+c_{u}\right)}{4 \widetilde{\beta}-\theta^{2}}, \\
\widetilde{s}_{1}^{*}=\frac{\theta^{2}\left[\widetilde{\alpha}-\tilde{\beta}\left(c_{0}+c_{1}+c_{u}\right)\right]^{2}}{\left(4 \widetilde{\beta}-\theta^{2}\right)^{2}} .
\end{gathered}
$$

If $\left(2 \widetilde{\alpha} \widetilde{\beta}-2 \widetilde{\beta}^{2}\left(c_{0}+c_{1}\right)-\left(4 \widetilde{\beta}-\theta^{2}\right) q_{T}^{*}\right) / 2 \widetilde{\beta}^{2}<c_{u}$, the Lagrangian multiplier $\lambda>0$, which means that $\widetilde{\alpha}-\widetilde{\beta} \widetilde{p}+\theta \sqrt{\widetilde{s}}-$ $q_{T}^{*}=0$. From Kuhn-Tucker condition, we obtain

$$
\tilde{p}_{2}^{*}=\frac{\beta^{2}\left(2 \widetilde{\beta}-\theta^{2}\right)}{\widetilde{\beta}^{2}\left(2 \beta-\theta^{2}\right)}\left(\beta p^{*}-\alpha\right)+\frac{\widetilde{\alpha}}{\widetilde{\beta}}, \quad \widetilde{s}_{2}^{*}=\frac{\beta^{2}}{\widetilde{\beta}^{2}} s^{*} .
$$


Similarly, if $\left(2 \widetilde{\alpha} \widetilde{\beta}-2 \widetilde{\beta}^{2}\left(c_{0}+c_{1}\right)-\left(4 \widetilde{\beta}-\theta^{2}\right) q_{T}^{*}\right) / 2 \widetilde{\beta}^{2} \leq-c_{s}$, the optimal solution of (A.2) is

$$
\begin{gathered}
\tilde{p}_{3}^{*}=\frac{2 \widetilde{\alpha}+\left(2 \widetilde{\beta}-\theta^{2}\right)\left(c_{0}+c_{1}-c_{s}\right)}{4 \widetilde{\beta}-\theta^{2}}, \\
\widetilde{s}_{3}^{*}=\frac{\theta^{2}\left[\widetilde{\alpha}-\widetilde{\beta}\left(c_{0}+c_{1}-c_{s}\right)\right]^{2}}{\left(4 \widetilde{\beta}-\theta^{2}\right)^{2}} .
\end{gathered}
$$

If $\left(2 \widetilde{\alpha} \widetilde{\beta}-2 \widetilde{\beta}^{2}\left(c_{0}+c_{1}\right)-\left(4 \widetilde{\beta}-\theta^{2}\right) q_{T}^{*}\right) / 2 \widetilde{\beta}^{2}>-c_{s}$, the optimal solution of (A.2) is

$$
\widetilde{p}_{2}^{*}=\frac{\beta^{2}\left(2 \widetilde{\beta}-\theta^{2}\right)}{\widetilde{\beta}^{2}\left(2 \beta-\theta^{2}\right)}\left(\beta p^{*}-\alpha\right)+\frac{\widetilde{\alpha}}{\widetilde{\beta}}, \quad \widetilde{s}_{2}^{*}=\frac{\beta^{2}}{\widetilde{\beta}^{2}} s^{*} .
$$

Combining these two cases, we can obtain Corollary 3.

\section{Conflict of Interests}

The authors declare that there is no conflict of interests regarding the publication of this paper.

\section{Acknowledgments}

This research was supported in part by the National Natural Science Foundation of China under Grants nos. 71171011, 71072157, and 91224001 and the New Century Excellent Talents in Universities scheme (NCET-12-0756).

\section{References}

[1] X. Qi, J. F. Bard, and G. Yu, "Supply chain coordination with demand disruptions," Omega, vol. 32, no. 4, pp. 301-312, 2004.

[2] T. Xiao, G. Yu, Z. Sheng, and Y. Xia, "Coordination of a supply chain with one-manufacturer and two-retailers under demand promotion and disruption management decisions," Annals of Operations Research, vol. 135, no. 1, pp. 87-109, 2005.

[3] W. Zhang, J. Fu, H. Li, and W. Xu, "Coordination of supply chain with a revenue-sharing contract under demand disruptions when retailers compete," International Journal of Production Economics, vol. 138, no. 1, pp. 68-75, 2012.

[4] J. Raju and Z. J. Zhang, "Channel coordination in the presence of a dominant retailer," Marketing Science, vol. 24, no. 2, pp. 254262, 2005.

[5] T. Xiao and X. Qi, "Price competition, cost and demand disruptions and coordination of a supply chain with one manufacturer and two competing retailers," Omega, vol. 36, no. 5, pp. 741-753, 2008.

[6] T. Xiao, X. Qi, and G. Yu, "Coordination of supply chain after demand disruptions when retailers compete," International Journal of Production Economics, vol. 109, no. 1-2, pp. 162-179, 2007.

[7] K. Chen and T. Xiao, "Demand disruption and coordination of the supply chain with a dominant retailer," European Journal of Operational Research, vol. 197, no. 1, pp. 225-234, 2009.

[8] G. P. Cachon, "Supply chain coordination with contracts," Handbooks in Operations Research and Management Science, vol. 11, pp. 227-339, 2003.
[9] F. Bernstein and A. Federgruen, "Pricing and replenishment strategies in a distribution system with competing retailers," Operations Research, vol. 51, no. 3, pp. 409-426, 2003.

[10] G. P. Cachon and M. A. Lariviere, "Supply chain coordination with revenue-sharing contracts: strengths and limitations," Management Science, vol. 51, no. 1, pp. 30-44, 2005.

[11] C. Koulamas, "A newsvendor problem with revenue sharing and channel coordination," Decision Sciences, vol. 37, no. 1, pp. 91$100,2006$.

[12] Y. Gerchak and Y. Wang, "Revenue-sharing vs. wholesaleprice contracts in assembly systems with random demand," Production and Operations Management, vol. 13, no. 1, pp. 23-33, 2004.

[13] I. Giannoccaro and P. Pontrandolfo, "Supply chain coordination by revenue sharing contracts," International Journal of Production Economics, vol. 89, no. 2, pp. 131-139, 2004.

[14] X. Zou, S. Pokharel, and R. Piplani, "Channel coordination in an assembly system facing uncertain demand with synchronized processing time and delivery quantity," International Journal of Production Research, vol. 42, no. 22, pp. 4673-4689, 2004.

[15] C. T. Linh and Y. Hong, "Channel coordination through a revenue sharing contract in a two-period newsboy problem," European Journal of Operational Research, vol. 198, no. 3, pp. 822-829, 2009.

[16] M. Xu, Q. Wang, and L. Ouyang, "Coordinating contracts for two-stage fashion supply chain with risk-averse retailer and price-dependent demand," Mathematical Problems in Engineering, vol. 2013, Article ID 259164, 12 pages, 2013.

[17] O. D. Palsule-Desai, "Supply chain coordination using revenuedependent revenue sharing contracts," Omega, vol. 41, no. 4, pp. 780-796, 2013.

[18] C.-F. Hsueh, "Improving corporate social responsibility in a supply chain through a new revenue sharing contract," International Journal of Production Economics, vol. 151, pp. 214-222, 2014.

[19] S. Sang, "Supply chain contracts with multiple retailers in a fuzzy demand environment," Mathematical Problems in Engineering, vol. 2013, Article ID 482353, 12 pages, 2013.

[20] G. Xu, B. Dan, X. Zhang, and C. Liu, "Coordinating a dualchannel supply chain with risk-averse under a two-way revenue sharing contract," International Journal of Production Economics, vol. 147, pp. 171-179, 2014.

[21] K. Govindan and M. N. Popiuc, "Reverse supply chain coordination by revenue sharing contract: a case for the personal computers industry," European Journal of Operational Research, vol. 233, no. 2, pp. 326-336, 2014.

[22] X. Feng, I. Moon, and K. Ryu, "Revenue-sharing contracts in an N-stage supply chain with reliability considerations," International Journal of Production Economics, vol. 147, pp. 20 29, 2014.

[23] S. Huang, C. Yang, and X. Zhang, "Pricing and production decisions in dual-channel supply chains with demand disruptions," Computers \& Industrial Engineering, vol. 62, no. 1, pp. 70-83, 2012.

[24] D. Lei, J. Li, and Z. Liu, "Supply chain contracts under demand and cost disruptions with asymmetric information," International Journal of Production Economics, vol. 139, no. 1, pp. 116126, 2012.

[25] Y. He and S. Wang, "Analysis of production-inventory system for deteriorating items with demand disruption," International Journal of Production Research, vol. 50, no. 16, pp. 4580-4592, 2012. 
[26] E. Cao, C. Wan, and M. Lai, "Coordination of a supply chain with one manufacturer and multiple competing retailers under simultaneous demand and cost disruptions," International Journal of Production Economics, vol. 141, no. 1, pp. 425-433, 2013.

[27] X. Wang and Y. Wang, "Coordination and pricing for closedloop supply chain based on demand and collection disruptions," Computer Integrated Manufacturing Systems, vol. 19, no. 3, pp. 624-630, 2013.

[28] E. Tavakoli and M. Mirzaee, "Coordination of a three-level supply chain under disruption using profit sharing and return policy contracts," International Journal of Industrial Engineering Computations, vol. 5, no. 1, pp. 139-150, 2014.

[29] T. Geylani, A. J. Dukes, and K. Srinivasan, "Strategic manufacturer response to a dominant retailer," Marketing Science, vol. 26, no. 2, pp. 164-178, 2007.

[30] K. Chen and P. Zhuang, "Disruption management for a dominant retailer with constant demand-stimulating service cost," Computers \& Industrial Engineering, vol. 61, no. 4, pp. 936-946, 2011.

[31] J. Useem, "One nation under Wal-mart how retailing's superpower-and our biggest most admired company-is changing the rules for corporate America," Fortune, p. 65, 2003.

[32] D. L. Rubinfeld and R. S. Pindyck, Microeconomics, PrenticeHall, 8th edition, 2013.

[33] A. P. Jeuland and S. M. Shugan, "Managing channel profits," Marketing Science, vol. 27, no. 1, pp. 52-69, 2008. 


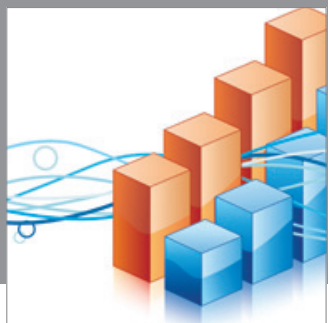

Advances in

Operations Research

mansans

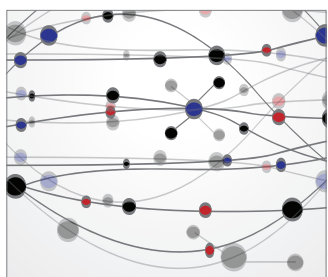

The Scientific World Journal
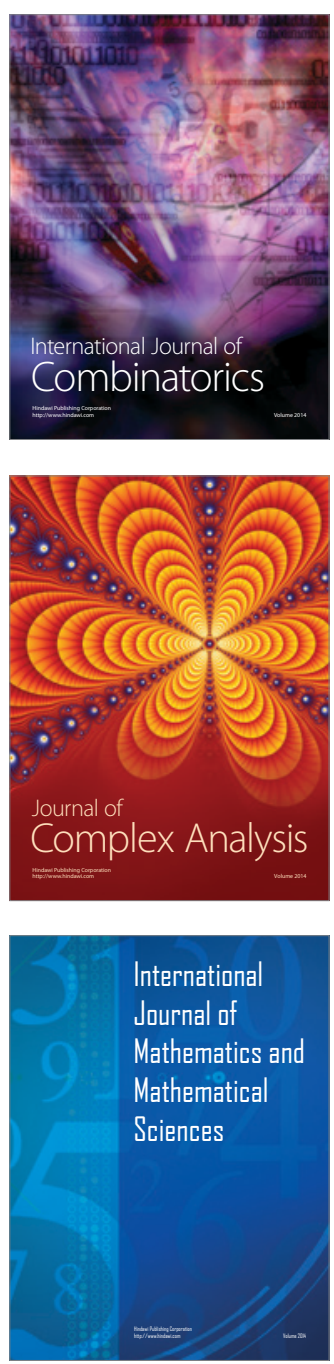
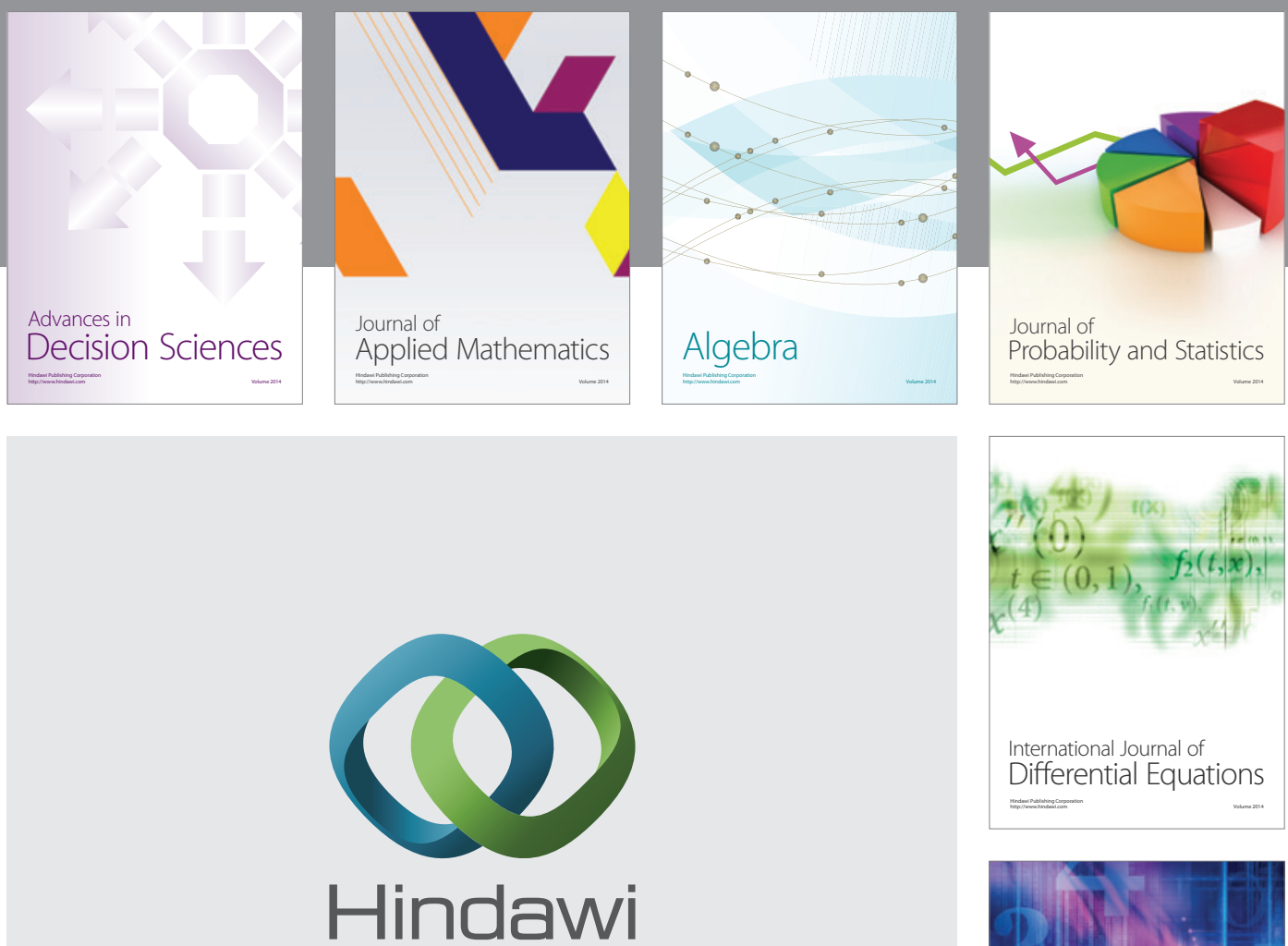

Submit your manuscripts at http://www.hindawi.com
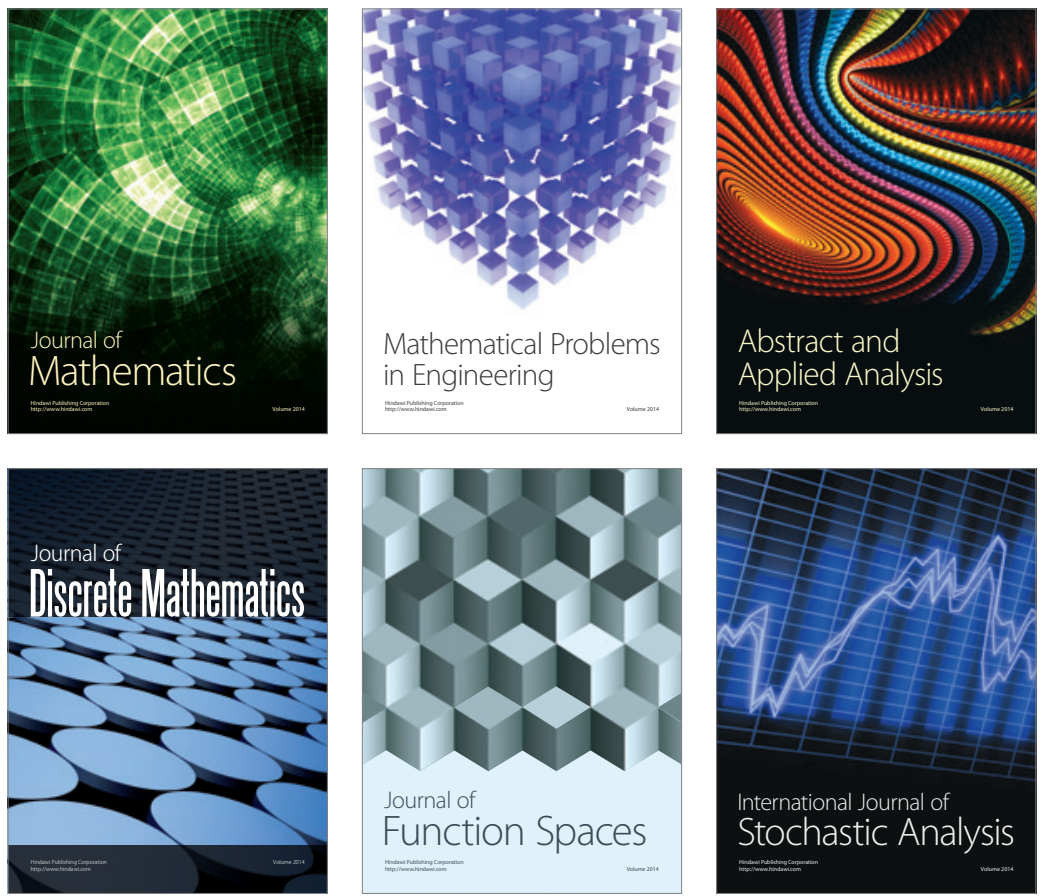

Journal of

Function Spaces

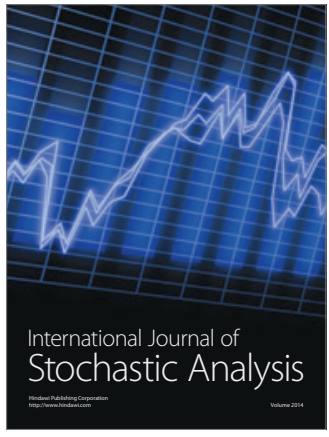

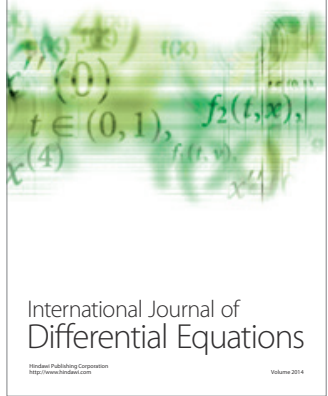
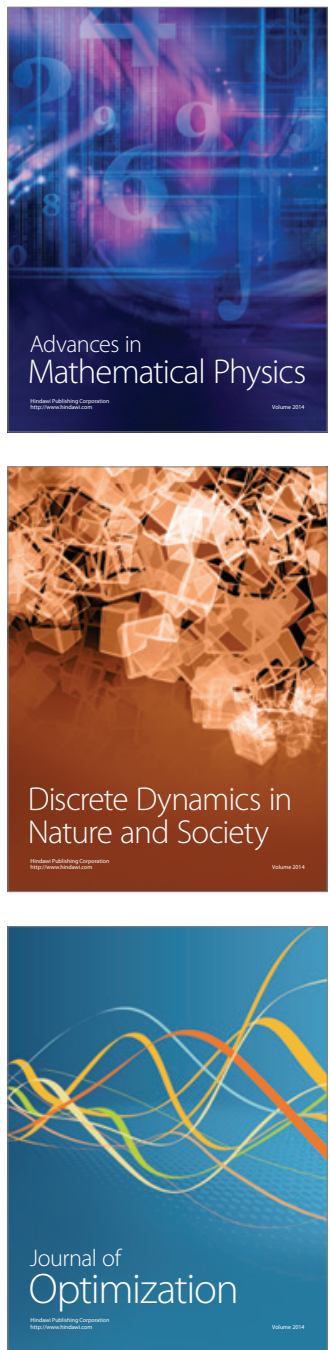